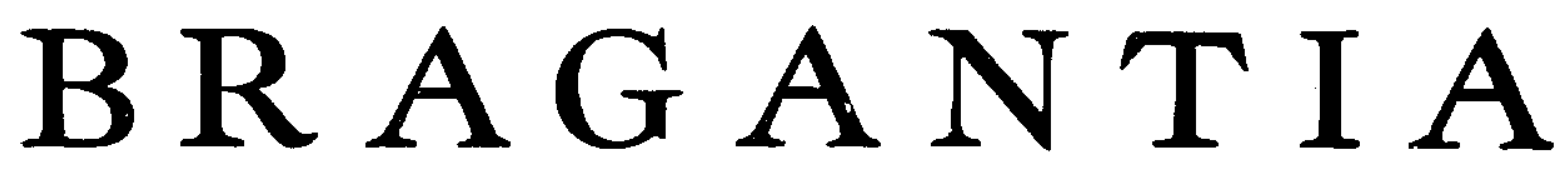

Boletim Técnico da Divisão de Experimentação e Pesquisas I N S T I T UTO A GRONÔMICO

\begin{tabular}{llll}
\hline \hline Vol. 13 & Campinas, junho de 1954 & N. ${ }^{\circ} 11$ \\
\hline \hline
\end{tabular}

\title{
NOVO NEMATÓDEO PARASITO DA BATATINHA (*)
}

I.uiz Gonzaga E. Londello e Adiel Paes Leme /amith, engenheiros-agrônomos, Escola Superior de Agricultura "Luis de Queiroz", Universidade de S. Paulo e O. J. Boock, engenheiro-agrônomo, Seção de Raízes e Tubérculos, Instituto Agronômico de Campinas

\section{RESUMO}

Pratylenchus steineri n. sp. (Nematoda, Heteroderidæ), novo parasito da batatinha (Solanum tuberosum I.), é descrita. A sua importância reside no fato do determinar, nos tubérculos, pequenas e numerosas pústulas, desvalorizando o produto proveniente de terrenos infestados. $\Lambda$ s lesões são superficiais, uma vez que no interior dos tubérculos os tecidos permanecem sadíos.

Dá-se a distribuição da espécie no Estado de São Paulo, são fornecidas algumas anotações bionômicas, bem como outras relativas à sua importância como parasito. São também indicadas medidas de contrôle (seleção dos tubérculos-semente e rotação de culturas).

\section{1 - INTRODUÇÃO}

Até há pouco tempo, conhecia-se, no Brasil, apenas um Nematódeo prejudicial à cultura da batatinha e que era Meloidogyne incognita (Kofoid \& White, 1919) Chitwood, 1949, da família Heteroderidæ, durante muitos anos conhecido como Heterodera marioni (Cornu, 1879) Goodey, 1932. Este parasițo provoca, nos tubérculos, deformações vulgarmente conhecidas como "pipocas" ou "verrugas", e que são altamente prejudiciais, não só por afetarem a aparência do produto, tornando-o impróprio ao comércio, como, principalmente, pelo deterioramento que determinam durante o tempo em que as batatinhas ficam armazenadas. Os danos podem ser consideráveis, máxime nas culturas realizadas em terrenos arenosos e no período chuvoso e quente do ano.

Em 195̃1, nova espécie foi constatada em uma região batateira do Estado de São Paulo (Sapecado) e descrita por Lordello (2) como Xiphinema brasiliense (família Dorylaimidæ). Trata-se de um ectoparasito, cuja ação nociva, contudo, ainda não é bem conhecida. Aliás, a presença de um longo estilete em Nematódeos livres no solo é considerada indicação de ectoparasitismo.

Uma terceira espécie é descrita nêste trabalho, Pratylenchus steineri n. sp., da família Heteroderidæ, que ocasiona nos tubérculos as mesmas lesões que, nos Estados Unidos, são devidas a $P$. scribneri Steiner, $1943(4,7)$.

(*) Recebido para publicação em 12 de março de 1954. 
O nome da espécie é dedicado ao Dr. G. Steiner, Diretor da Divisão de Nematologia do Departamento de Agricultura dos Estados Unidos, em reconhecimento pelos seus incansáveis auxílios, orientando-nos durante a sua permanência no Instituto Agronômico de Campinas, remetendo-nos literatura e fornecendo sugestoes.

\section{2 - DESCRIÇÃO DE PRATYLENCHUS STEINERI N. SP.}

$q=408,51-653,30$ micros $; a=17,7-27,3 ; b=5,8-10,1 ; c=17,8-$ $-28,3 ; V=82,3-85,9 \%$.

Dimensões - Os dados resumidos acima encontram-se no quadro 1, onde são fornecidos os resultados da mensuração de 10 fêmeas. No quadro 2, dão-se as medidas de três larvas.

Qundro 1. - Resultados da mensuração de 10 fêmeas cle Pratylenchus steineri n. sp.

\begin{tabular}{|c|c|c|c|c|c|c|c|c|c|c|}
\hline \multirow[t]{2}{*}{ Fêmea } & 1 & 2 & 3 & 4 & 5 & 6 & 7 & 8 & 9 & 10 \\
\hline & $\mu$ & $\mu$ & $\mu$ & $\mu$ & $\mu$ & $\mu$ & $\mu$ & $\mu$ & $\mu$ & $\mu$ \\
\hline Comp. total & 408,51 & 540,09 & 477,36 & 540,09 & 653,30 & 535,50 & 501,84 & 650,25 & 515,61 & 633,42 \\
\hline $\begin{array}{l}\text { Largura } \\
\text { Comp. do esôf }\end{array}$ & $\begin{array}{l}21,42 \\
70,38\end{array}$ & $\begin{array}{l}29,07 \\
68,85\end{array}$ & 26,00 & $\begin{array}{l}26,00 \\
68,85\end{array}$ & $\begin{array}{l}29,07 \\
84,15\end{array}$ & $\begin{array}{l}21,42 \\
78,03\end{array}$ & $\begin{array}{l}18,36 \\
71,91\end{array}$ & $\begin{array}{l}29,07 \\
64,26\end{array}$ & 29,07 & $\begin{array}{l}29,07 \\
65,79\end{array}$ \\
\hline Dist. da cabeça & & & & & & & & & & \\
\hline $\begin{array}{l}\text { vulva } \\
\text { omp. da cauda... }\end{array}$ & 336,60 & $\begin{array}{r}\mathbf{4 6 3}, 59 \\
, 48\end{array}$ & 410,04 & $\mid \begin{array}{r}463,59 \\
0,40\end{array}$ & 561,50 & 460,53 & 425,34 & $\mathbf{5 5 8 , 4 5}$ & 439,11 & 543,15 \\
\hline $\begin{array}{l}\text { Comp. da cauda } \\
\text { Comp. do estilete.- }\end{array}$ & $\begin{array}{l}22,95 \\
19,89\end{array}$ & $\begin{array}{l}24,48 \\
19,89\end{array}$ & $\begin{array}{l}24.48 \\
19.89\end{array}$ & $\begin{array}{l}21,42 \\
19.89\end{array}$ & $\begin{array}{l}30,60 \\
19,89\end{array}$ & $\begin{array}{l}26,00 \\
18,36\end{array}$ & $\begin{array}{l}26,00 \\
19,89\end{array}$ & $\begin{array}{l}22,95 \\
18,36\end{array}$ & $\begin{array}{l}24.48 \\
19.89\end{array}$ & $\begin{array}{l}26,00 \\
18,36\end{array}$ \\
\hline -.............. & 19,00 & 18,60 & 18,30 & 20,70 & 22,40 & 25,00 & 27,30 & 22,30 & 17,70 & 21,70 \\
\hline & 5,80 & 7,80 & 7,80 & 7,90 & $\mathbf{7 , 7 0}$ & 6,30 & 6,90 & 10,10 & 7,60 & 9,60 \\
\hline$=-$ & $\begin{array}{l}17,80 \\
82,30\end{array}$ & 85,80 & $\begin{array}{l}19,50 \\
85, \varepsilon 0\end{array}$ & $\begin{array}{l}25,20 \\
85,80\end{array}$ & $\begin{array}{l}21,30 \\
85,90\end{array}$ & $\begin{array}{l}22,50 \\
86,50\end{array}$ & $\begin{array}{l}19,30 \\
84,70\end{array}$ & $\begin{array}{l}28,30 \\
85,80\end{array}$ & $\begin{array}{l}21,06 \\
85,10\end{array}$ & $\begin{array}{l}24,30 \\
85,60\end{array}$ \\
\hline & & & & & & & & & 74,9 & \\
\hline Tal & & 24,48 & & & $24,4 \varepsilon$ & & & & 27,54 & 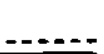 \\
\hline
\end{tabular}

Quadro 2. - Resultados da mensuração de três larvas de Pratylenchus steineri n. sp.

\begin{tabular}{|c|c|c|c|}
\hline Larva & 1 & 2 & 3 \\
\hline & $\mu$ & $\mu$ & $\mu$ \\
\hline Comprimento total & 468,18 & 304,47 & 327,42 \\
\hline Iargura & 33,66 & 19,89 & 22,95 \\
\hline Comprimento do esôfago & 67,32 & 50,49 & 65,79 \\
\hline Comprimento do estilete .. & 16,83 & 15,30 & 16,83 \\
\hline Cauda & 29,07 & 19,89 & 21,42 \\
\hline
\end{tabular}

Forma do corpo - Pràticamente cilíndrica, atenuando-se mais ou menos igualmente para as duas extremidades.

Cutícula - Transparente, delgada e inteiramente estriada no sentido transversal. A partir da vulva e, mais ainda, a partir do ânus para a extremidade posterior, as estriações se acentuam. A čluda compreende cêrca de 

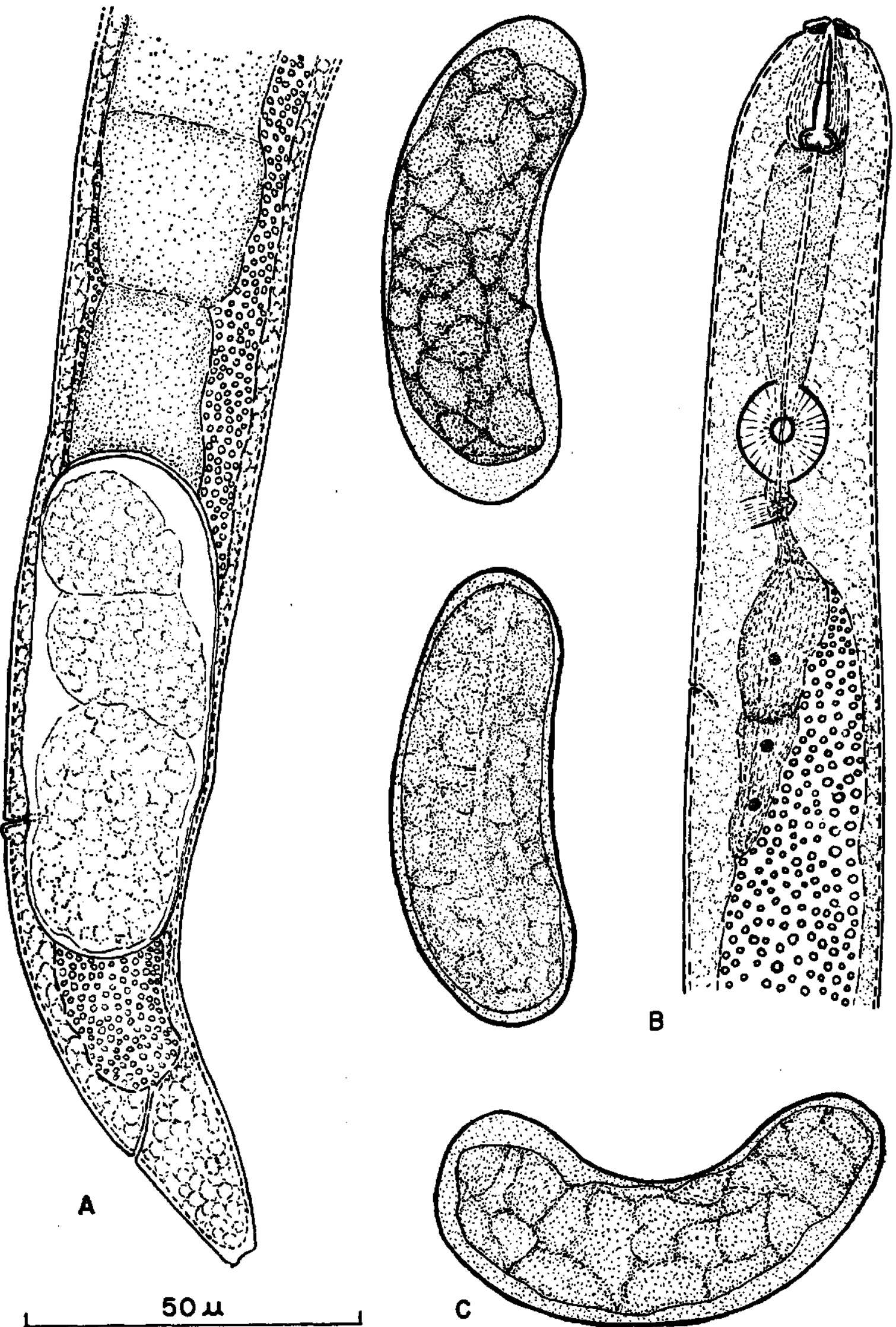

Figura 1.-Pratylenchus steineri n. sp. $A$-extremidade caudal da fêmea; $B$-porção anterior; $C$-ovos em segmentação. 
17 estrias; o término caudal, contudo, apresenta-se desprovido de qualquer estriação.

Os campos laterais estendem-se das vizinhanças do bulbo mediano do esôfago até a cauda e deixam ver 4 linhas ou incisuras paralelas, as quais, em alguns exemplares, aproximam-se entre si pouco além da vulva. Na altura do poro excretor, numa das fêmeas estudadas, a distância entre as incisuras externas era de 5,04 micros. Não se constatou a organização dos campos laterais, aquém da altura da vulva, como assinalado por Sher \& Allen (3) em Pratylenchus minyus Sher \& Allen, 1953, que é a espécie afim.

Cabeça - Lábios com dois anéis, mostrando, portanto, uma única estriação transversal. Margens laterais dos lábios arredondadas. Papilas labiajs bastante obscuras. De acôrdo com Thorne (8), em Pratylenchus há um círculo inferior de 6 papilas e outro superior de 8 .

Cauda - A forma da cauda mostra variações. Ora ela se apresenta com a extremidade perfeitamente arredondada; ora mostra uma depressão mais ou menos pronunciada, tal como a figura que apresentamos. A forma do extremo da cauda das larvas enquadra-se no primeiro caso.

Aparêlho digestivo - Estilete com bulbo basal arredondado e bem desenvolvido. Trata-se, no caso, de um sTomato-sTYLET, que aportuguesamos para estômato-estilete, uma vez que é o resultado da transformação de tôda a cavidade bucal. Na superfamília Dorylaimoidea, o estilete resulta da transformação de um dente e é denominado odonto-estilete (oDonTo-STYLET) (5). Nestas condições, em Pratylenchus o estilete representa o sтомA, que é divisivel em três partes segundo a terminologia que, ao que parece, foi originalmente introduzida por Christie, Chitwood e Steiner (6) ; a parte anterior do estilete, ou ponta, constitui o protorábdio; a porção seguinte, mediana, é o mesometarábdio e o bulbo basal constitui o telorábdio.

O esôfago compreende três partes : corpo, bulbo mediano e região bulbar, esta última apresentando as três glândulas esofageanas. $O$ bulbo mediano é arredondado e provido de um aparelho valvular. O seu diâmetro é superior à metade da largura do corpo tomada na mesma altura. Em duas fêmeas, o diâmetro do bulbo mediu 12,24 micros e a largura, 21,42 micros.

Os núcleos das três glândulas esofageanas nem sempre são fàcilmente visíveis. O conduto da glândula dorsal abre-se no canal do esôfago, bem próximo ao bulbo do estilete.

A junção do esôfago com o intestino é freqüentemente bastante obscura, para o que concorrem as glândulas esofageanas.

$O$ intestino não apresentou nenhum característico que exigisse atenção especial ; aliás, êle se apresenta invariàvelmente cheio de grânulos esféricos mais ou menos escurecidos, com freqüência associados a matérias formando corpos arredondados relativamente grandes. Em uma fêmea o reto mediu 10,7 micros, sendo inferior ao diâmetro do corpo tomado na altura do ânus.

Poro excretor - De localização bastante variável, pois constatamo-lo distanciado desde 55,08 até 90,27 micros da frente da cabeça. 
Aparêlho reprodutor - Um ovário, anterior em relação à vulva, tal como acontece com tôdas as espécies do gênero. $O$ ovário é completamente distendido, ou melhor, nunca se apresenta reflexo, e consiste de uma linha simples de oócitos, com ou sem regiões de linhas múltiplas. Nunca o ovário atinge a base do esôfago.

Descrevemos, a seguir, os ovários de duas fêmeas, os quais representam os dois tipos verificados em Pratylenchus steineri; nos dois casos não há a organização registrada por Sher \& Allen (3) em $P$. minyus, no qual o ovário consta de uma linha simples de oócitos, exceto na extremidade anterior, onde aparecem linhas múltiplas : $a$ ) ovário com linha simples de oócitos em tôda a sua extensão, perfazendo um total de 14 elementos ; b) o tubo ovariano inicia-se por uma linha simples de 3 ou 4 oócitos e depois continua-se por uma linha dupla com cêrca de 8 oócitos, que logo passa a ser simples (11 oócitos) perfazendo, então, o total de 22 ou 23 células reprodutoras.

$\mathrm{O}$ oviduto é celular. Um único ôvo é visto no útero, nas proximidades da vulva, prestes a ser lançado para o exterior. Quando em tal situação, quer-nos parecer que o ôvo pode se mostrar em estado inicial de segmentação. Pela dissecação das lesões dos tubérculos atacados, obtivemos ovos livres que, contudo, apresentavam-se em parte sem qualquer indício de tal fenômeno. Sher \& Allen (3) afirmam que em Pratylenchus os ovos são expulsos antes que a segmentação ocorra.

Os ovos são alongados, de cório perfeitamente liso, rombudos nas extremidades e deprimidos na porção média; tal depressão resulta do fato de uma das faces do ôvo apresentar-se ligeiramente côncava e a face oposta ligeiramente convexa (ôvo reniforme). Entretanto, quando encerrado no útero, nas adjacências da vulva, o ôvo não se apresenta deprimido na região mediana. Vê-se assim que, ao ganhar o exterior, êle sofre alteração na forma.

No quadro 1 são fornecidas as dimensర̃es de ovos contidos no tubo uterino. O comprimento de ovos livres variou de 64,26 a 74,97 micros e a largura, de 21,40 a 25,0 micros. O diâmetro do ôvo representa 84,4 a $94,8 \%$ da largura do corpo.

A vulva é representada por uma fenda localizada a $336,60-561,50$ micros da frente da cabeça. Vista de frente, a vulva se apresenta como uma fenda transversal, cuja abertura é maior que a metade da largura do corpo tomada nessa região. Em uma fêmea, a abertura vulvar era de 13,77 micros e a largura do corpo, 21,42 micros.

Não pudemos verificar a presença de espermateca. Aliás, em mais da metade das espécies do gênero, os machos são muito raros ou mesmo desconhecidos e o exame cuidadoso dos órgãos genitais de centenas de fêmeas dessas espécies não revelou a presença de espermateca e mesmo de espermatozóides. Nas espécies cujos machos são comuns, o exame das fêmeas tem revelado a presença de espermateca.

Larvas - No quadro 2, como já foi dito, são fornecidas as medidas de três formas jovens. Trata-se, por certo, de larvas em diferentes estádios. Em qualquer delas, a forma do extremo da cauda é arredondada, não tendo sido verificada a depressão existente na cauda das fêmeas. 


\section{3 - DIAGNOSE}

A espécie próxima de Pratylenchus steineri é, como se disse, $P$. minyus Sher \& Allen, 1953, da qual, contudo, difere por possuir estilete mais longo, pela forma da cauda e por detalhes na organização do ovário e dos campos laterais.

Com a descrição de $P$. steineri, a chave para a separação das formas conhecidas, cuja região labial possui apenas urna estriação (dois anéis), passa a ser a seguinte :

A. Margem lateral dos lábios angular

P. brachyurus (Godfrey, 1929) Goodey, 1951

Margem lateral dos lábios arredondada

B. Corpo longo e delgado (comp. $=400-700$ micros, $a=25-40$ ), machos numerosos …......... coffex (Zimmerman, 1898) Goodey, 1951

Corpo curto e relativamente grosso (comp. $=300-670$ micros, $a=17,70$ $-27,30$ ), machos raros ou desconhecidos

C. Distância da frente da cabç̧a à vulva $(V)$ valendo $75-80 \%$ do comprimento total do corpo $P$. seribneri Steiner, 1943

A mesma distância valendo $80-88 \%$

I). Estilete curto (16-18 micros), campos laterais, na altura da vulva, cortados por linhas oblíquas; machos conhecidos ... P. minyus Sher \& Allen, 1953

Estilete longo (18,36-19,89 micros), campos laterais normais ; machos desconhecidos P. steineri n. sp.

As espécies cuja região labial possui 3 ou 4 anéis (2 ou 3 estriaçðes), são as seguintes, a primeira das quais constitui o genótipo : Pratylenchus pratensis (de Man, 1880) Filipjev, 1936 ; P. penetrans (Cobb, 1917) ?; $P$. vulnus Allen \& Jensen, 1951 ; P. zeae Grahan, 1951 ; P. thornei Sher \& Allen, 1953 e $P$. goodeyi Sher \& Allen, 1953.

\section{4 - DISTRIBUIÇÃO DA ESPÉCIE}

Até o momento, foram examinados tubérculos atacados por Pratylenchus steineri procedentes das localidades de Campinas, Capão Bonito, Louveira, Piracicaba e Sapecado, tôdas no Estado de São Paulo.

\section{5 - NOTAS BIONÔMICAS E IMPOR'TANCIA DE PRATYLENCHUS STEINERI}

A espécie determina, nos tubérculos, pequenas e numerosas pústulas, as quais, como ficou dito, parecem ser bastante semelhantes àquelas que, nos Estados Unidos, são devidas a Pratylenchus scribneri. Batatinhas atacadas sofrem, no armazenamento, um murchamento bem mais pronunciado do que os tubérculos sadios. Podridões não ocorrem, ao contrário do que se verifica quando se trata de infestação por Meloidogyne incognita. 


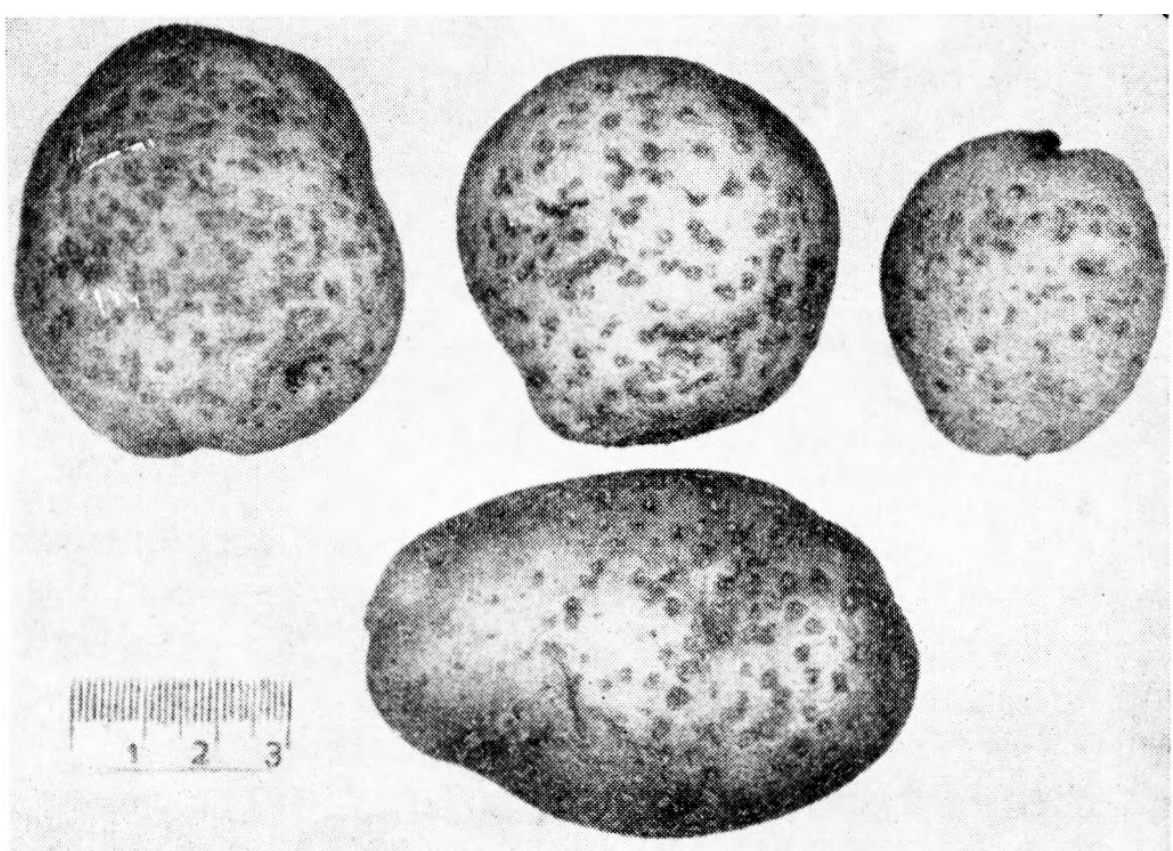

Figura 2. - Tubérculos de batatinha mostrando lesões devidas ao ataque de Pratylenchus steineri n. sp.

As anotações obtidas por ocasião da colheita de experimentos conduzidos pela Secção de Raízes e Tubérculos, do Instituto Agronômico de Campinas, vêm mostrando que os ataques pela espécie tendem a aumentar, podendo mesmo constituir mais um problema sério para a cultura, devido à desvalorização do produto colhido.

Apenas a casca e região subcortical são atingidas pela pústula. Como se vê, trata-se de lesões superficiais, suficientes, contudo, para depreciar grandemente os tubérculos sob o ponto de vista comercial. No interior dos tubérculos os tecidos permanecem sadios.

A dissecação das pústulas, em água, ao microscópio entomológico, permitiu obter tôdas as fases da evolução do parasito (ovos, larvas e fêmeas), com exceção de machos. Deve tratar-se de uma espécie monossexual.

Os indivíduos não saem dos tecidos pela sua própria ação. E retirá-los cuidadosamente com o auxílio de agulhas. Livres na água, pràticamente não realizam movimentos; são de fato extremamente morosos, pois poucas vêzes foram vistos movendo-se, e muito lentamente.

Exames procedidos em amostras de solo dos locais onde se colheram tubérculos desfigurados por $P$. steineri, não revelaram a presença de exemplares pertencentes à espécie, nem mesmo ao gênero, embora outras formas tivessem sido extraídas.

Apezar de não ser possível oferecer dados numéricos, verificou-se, contudo, que nos tubérculos atacados há um número de indivíduos bem inferior àquele que se constata quando se trata de $P$. scribneri, pois Steiner (7) calculou entre 12 e 15 mil exemplares a população presente num tubérculo desfigurado pela referida espécie americana. 
Das lesões devidas a $P$. steineri também se extraiu, com freqüência, uma espécie do gênero Helicotylenchus Steiner, 1945, cujo estudo será feito oportunamente. Eucephalobus sp. e Ditylenchus sp. foram igualmente obtidos das mesmas pústulas. Por outro lado, uma outra espécie de Pratylenchus, ainda não estudada, parece associar-se a $P$. steineri, sendo, porém, pouco abundante.

Num campo de observação de batatinha, instalado na Estação Experimental de Capão Bonito, a percentagem de tubérculos provenientes de "seedlings" afetados pelo verme foi de 14,1. Em Campinas, na Estação Experimental Central do Instituto Agronômico, verificou-se, também em dois lotes de observação de "seedlings", que as percentagens de ataque foram, respectivamente, de 23,6 e 34,7. Como as anotaçōes foram realizadas de maneira mais ou menos rápida, de acôrdo com as circunstâncias, é de se acreditar que tais valores possam ser consideràvelmente aumentados nas observações futuras, uma vez que em estado inicial as lesões podem fàcilmente passar despercebidas.

Nos trabalhos de experimentação conduzidos pelo Instituto Agronômico, as seguintes variedades mostraram-se suscetíveis ao ataque de Pratylenchus steineri: Eigenheimer, Konsuragis, Alpha, Estimata, Bintje, Ackersegen, Up to date, Frühgold, Katahdin, Ostbote, Saskia e Voran.

Para fins de anotaçóes durante os trabalhos com a cultura da batatinha nas Estações Experimentais do Instituto Agronômico, foi criado para Pratylenchus steineri o nome vulgar de "nematóide de pinta", a fim de diferençá-lo do agente causador das "pipocas" ou "verrugas". A literatura americana denomina as espécies de Pratylenchus, de "root-lesion nematodes" ou "meadow nematodes".

\section{6 - MEIOS DE COMBATE A PRATYLENCHUS STEINERI}

As seguintes medidas podem ser recomendadas, baseadas, aliás, no que se vem preconizando com relação à espécie americana $P$. scribneri $(1): a)$ seleção de tubérculos, utilizando no plantio sòmente aquêles que se mostrem perfeitamente sadios ; $b$ ) rotação de culturas, voltando a cultivar a batatinha sòmente dois ou três anos após a última cultura realizada.

\section{A NEW NEMATODE PARASITE OF POTATO TUBERS}

\section{SUMMARY}

A new nematode, Pratylenchus steineri (Heteroderidæ), that causes small pimples on the surface of potato tubers, is described. The disease is very similar to that incited by $P$. scribneri Steiner, 1943, in the United States. In the States, the disease was first studied by Scribner in 1889, who also determined its cause (1.). Many years later, Steiner (4) published the description of the parasite.

Pratylenchus steineri $\mathrm{n}$. sp. closely resembles $P$. minyis Sher \& Allen, 1953, from which it differs by its longer stylet, by the shape of its tail, and by some details in the organization of the ovary and lateral fields. $P$. sleineri can be easily distinguished from $P$. scribneri by the more posterior position of the vulva. 
All developmental stages of the new parasite were found to oceur in the potato lesions. The species seems to be monosexual since no males were found. A species of Helicotulcnchus, not yet studied, was also obtained from the pimples. In addition, Eucephalobus sp., Ditylenchus sp., and another species of Pratylenchus were found associated with $P$. steineri in rare instances.

In experimental potato fields belonging to the Instituto Agronômico de Campinas, Brazil, the percentage of tubers injured by the attack of $P$. steiner $i$ has ranged from 14.1 to 37.0 per cent in the last few years. The known area of distribution of the new speciss in the State of São Paulo, Brazil, is reported. Control measures are suggested that include (rop rolation for 2 or 3 years, combined with solection of healthy seed.

\section{LITERATURA CITADA}

1. DYKSTRA, T. P. Production of disease-free seed potatoes. Washington, U. S. Dep. of Agriculture, 1948. 64 p. (Circular n. ${ }^{\circ}$ 764)

2. LORDELLO, L. G. E. Xiphinema brasiliense, nova espécie de nematóide do Brasil, parasita de Solanum tuberosum T. Bragantia 11:[87]-90. 1951.

3. SHER, S. A. \& ALLEN, M. W. Revision of the genus Pratylenchus (Nematoda : Tylenchidx). Un. Calif. Publ. Koo. 57:441-470. 1953.

4. SHERBAKOFF, C. D. \& STANLEY, W. W. The more important diseases and insect pests of crops in Tennessee. Knoxville, Agric. exp. Station, 1949. 163 p. (Boletim n. ${ }^{\circ} 186$ )

5. STEINER, G. Curso de Nematologia geral de plantas. Campinas, Instituto agronômico, 1951. 22 p. [Mimeografado]

6. —_—_ The nematode Cylindrogaster longistoma (Stefanski) Goodey and its relationship. J. Parasitology 20:66-68. 1933.

7. ___ Plant nematodes the grower should know. Tallahassee, Dep. of Agricullure, 1949.47 p. (Boletim n. ${ }^{\circ} 131$ )

8. THORNE, G. On the classification of the Tylenchida, new order (Nematoda, Phasmidia). Proc. helm. Soc. Wash. 16:37-73. 1949. 